\title{
Effect of Node Density over the performance of DSR, TORA, and OLSR Routing Protocols of MANET
}

\author{
Naeem Raza \\ National Textile University \\ DCS, Faisalabad, Pakistan
}

\author{
Aized Amin Soofi \\ University of Central \\ Punjab \\ Pakistan
}

\author{
Habib Ur Rehman \\ National Textile University \\ DCS, Faisalabad, Pakistan
}

\author{
Mubashir Tariq \\ University of Central \\ Punjab \\ Pakistan
}

\begin{abstract}
Mobile Ad-hoc Network (MANET) is a network of heterogeneous and homogeneous wireless mobile nodes to offer provisionally communication facilities to users for the exchange of data packets without having the well-established infrastructure in a limited geographical area. Resourceconstrained mobile nodes are not a permanent part of the network instead mobile nodes are individualistically can join or leave the network at any time. Network topology, connectivity of nodes and routing information change dynamically based on multi-hop routing. The main focus of this research work is to evaluate the performance of DSR, TORA reactive routing protocols and OLSR proactive routing protocol of MANET under augmentation of Nodes Density investigation based on Random Way Point (RWP) mobility model. DSR, TORA, and OLSR protocols are simulated by using OPNET modeler 14.5 by creating three different scenarios. These protocols are compared and analyzed with respect to Wireless LAN delay, Wireless LAN throughput, Wireless LAN network load, Routing traffic send and Routing traffic received.
\end{abstract}

\section{General Terms}

Routing Protocols, MANET, Performance Evaluation, Nodes Density, Random Waypoint Mobility Model.

\section{Keywords}

MANET Routing Protocols, DSR, TORA, OLSR, Nodes Density.

\section{INTRODUCTION}

Wireless networks are capable of providing faster and fully distributed computations, communications anywhere and at any time making it possible for the wireless network nodes to exchange data without physically connected to each other's [1]. Mobile Ad-hoc Network (MANET) is emerged due to the rapid advancements in the field of wireless networks, advanced wireless communication technologies and the powerful mobile devices supported by the cellular networks and the internet. Instead of fixed infrastructure-based wireless networks, easily reconfigurable MANET has the potential to provide communications in case of natural disasters, such as earthquakes, fire and or flood [2]. Mobile nodes form MANET in a peer to peer (P2P) fashion without preexisting fixed infrastructure [3]. MANETs are self-creatable, selforganizable, self-configurable, easily deployable, highly fault resilient, flexible, adaptable oriented robust mobile networks [4]. High mobility of mobile nodes and lots of variations in the transmission range of these nodes makes network topology completely dynamic [5]. With the emergence of cheaper, smaller, battery-equipped, more advanced functioning, and powerful portable devices, MANETs have become a rapidly growing technique. Due to the emergence of Information and Communication Technology, MANETs are capable of providing multimedia services, surveillance, health monitoring, and remote education, etc. [6-10].

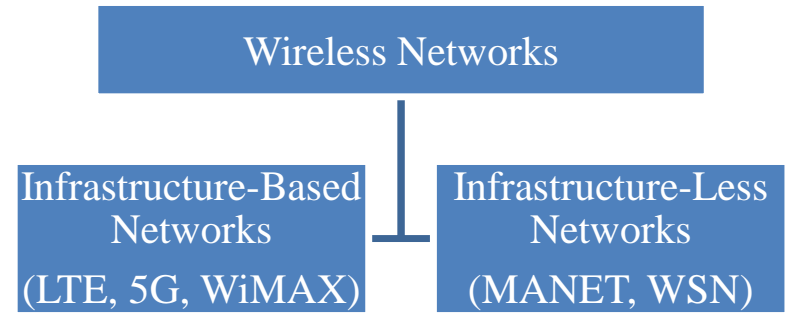

Fig 1: Wireless Networks Catagories

The rest of the paper is organized as follows. Section 2 highlighted the routing requirements as well as the working of DSR, TORA, and OLSR routing protocols of MANET, in section 3, simulation scenarios, parameters, and performance matrices selection, configuration, and experimentation were discussed. In section 4, simulation results, comparative analysis, and details were discussed. The last section concluded and summarized the overall research work.

\section{ROUTING IN MANET}

To exchange data packets in wireless networks, the first step is to find the best and shortest path from the traffic riginating source node to the traffic receiving destination node. These tasks are performed by the routing protocols and the routing algorithms. Routing protocols suggest the mobile nodes about topological information whereas routing algorithms form the shortest path by calculating the distances of all the connected nodes and links. Dijkstra and the Bellman-Ford is a commonly used routing algorithm [11]. Transmission Control Protocol over Internet Protocol(TCP/IP) protocol suite consists of four layers such as the application layer, transport layer, network layer, and data lin layer. The topmost application layer manages the applications, transport layer responsible for transferring reliably or unreliable data segments of related application-specific processes, network layer deals with data packets and IP addresses and data link layer deals with data frames based on Media Access Control (MAC) address [12]. In MANETs, mobile nodes do not only forward data packets but also support effective and strong routing functioning. MANET nodes form a multi-hop and dynamic topology network with bandwidth constraint communication links [13]. Mobile

nodes in MANET must learn its neighbors and path to reach the destinations using intermediate nodes in a multi-hop 
fashion and based on this knowledge transmit data packets. This is happened just because of ad-hoc routing protocols of MANET [14, 15]. Mobile nodes in MANET are resource-poor in terms of computations, memory, battery life and mobility. So, each node has a limited transmission range and they require multi-hop links to transfer data packets [16]. Various kinds of routing protocols proposed by the researchers to work in a MANET environment. Each of these must fundamentally base on link-state and distance vector routing algorithms [17]. There are several factors involved in MANET routing protocol performance optimizations and effectiveness such as geographical network area, nodes density, nodes speed, nodes mobility, mobility models, packet size, link bandwidth, the transmission range of each node, simulation time, simulation parameters, etc. [18]. Some of the common MANET Flat or Unicast routing protocols are highlighted in Fig. 2.

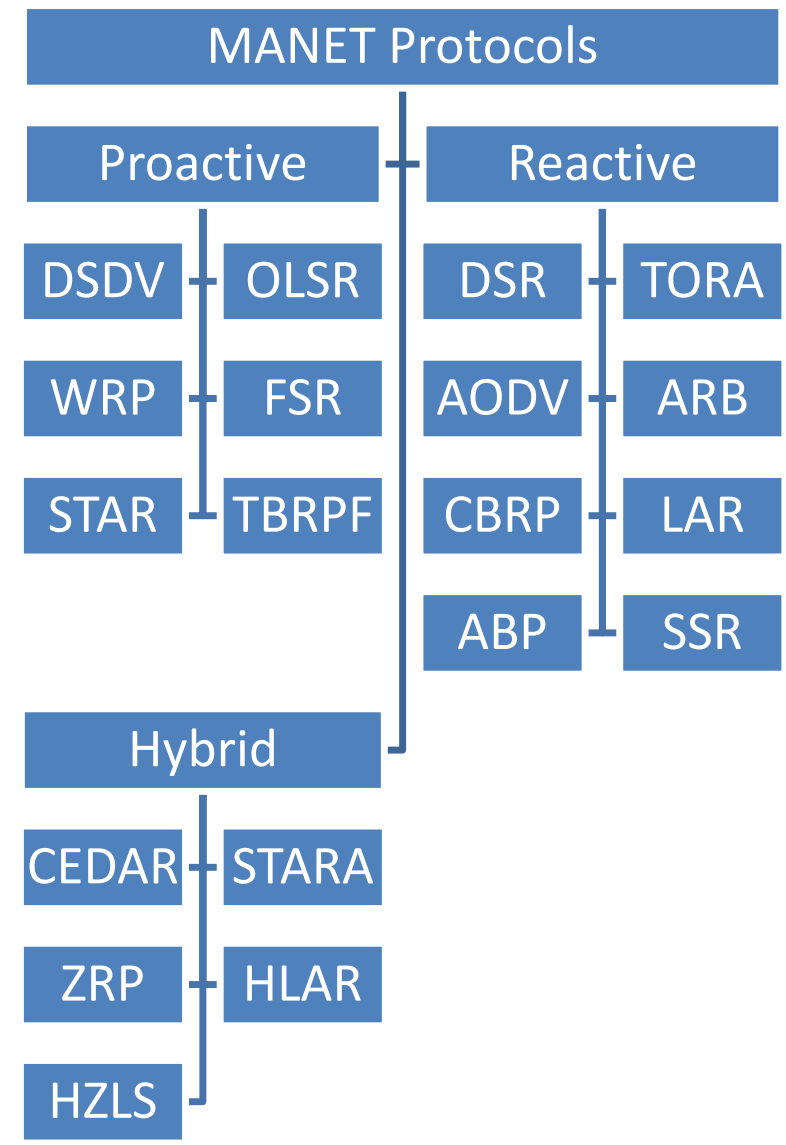

Fig 2: MANET Uni-Cast Routing Protocols [19-21]

\subsection{Optimized Link State Routing (OLSR)}

Optimized Link State Routing (OLSR) is a proactive or tabledriven routing protocol, it maintains the routing and dynamically changing topology information prior to the actual transmission of data packets to the network nodes. OLSR routing protocol is based on MultiPoint Relay (MPR), which minimizes the need to control data packets required for the maintain the routing and topological information for the efficient transmission of data packets. In MPR, nodes select the symmetric neighbor nodes to hop by hop and in a cascading fashion. This hierarchical approach maintains a list

of MPRs nodes to transmit data and forward messages in a flooded fashion and is maintaining the optimized routing and communication links. OLSR approach is inverse of the linkstate routing algorithm. Therefore, OLSR is less powerintensive [22]

\subsection{Dynamic Source Routing (DSR)}

Dynamic Source Routing (DSR) is a reactive or on-demand routing protocol, it discovers the routing and topology information at the time whenever transmission of data packets to the network nodes required. They require relatively high bandwidth demand for control data packets specifically instead of only for forwarding messages. DSR maintains the loop-free path rapidly in case of changing network paths. Each node adds the control packet in the forwarding path and caches the path information, results in minimizing the propagation delay with increased routing overhead [23].

\subsection{Temporary Ordered Routing Algorithm (TORA)}

Temporary Ordered Routing Algorithm (TORA) is a reactive or on-demand routing protocol, it discovers the routing and topology information at the time whenever transmission of data packets to the network nodes required. TORA is mainly based on the "Connection Traversal" phenomenon and it maintains the Directed Acyclic Graph (DAG) for network nodes. Based on DAG all the involved nodes in message forwarding send back the routing or path information to the source node from the destination node. In TORA limited administration is required for efficient routing-related control overheads. There may exist several intermediate paths between the source and destination nodes. By this fashion reroute establishment can easily be understood, recognized and configured quickly [24].

\section{SIMULATION SETUP}

In this research work, three network scenarios of MANET with the varying number of mobile wireless nodes $(25,50$ and 75) were created in OPNET modeler 14.5 as shown in Fig. 3, Fig. 4, and Fig. 5. MANET server was configured to provide communication facilities between the nodes, and the server in client/server architecture. To provide mobility to the nodes, the mobility configuration entity was configured by using Random Way Point (RWP) mobility model. MANET profile definition entity was used for nodes parameter settings. The application definition entity was used to generate FTP traffic. The simulated network is constructed to evaluate the effect of nodes density over the performance of DSR, TORA, and OLSR routing protocols of MANET. The simulation parameters are presented in Table 1.

Table 1. Simulation Parameters

\begin{tabular}{|c|c|}
\hline Parameters & Value/Size \\
\hline Simulation Area & $500 * 500$ Meters \\
\hline Simulation Time & 10 Minutes \\
\hline Maximum Speed & Uniform and $10 \mathrm{~m} / \mathrm{sec}$ \\
\hline Number of Nodes & $25,50,75$ \\
\hline Routing Protocols & DSR, TORA, OLSR \\
\hline Mobility Model & Random Way Point \\
\hline Traffic Type/ Application & CBR/FTP \\
\hline Packet Size & 1500 bytes \\
\hline
\end{tabular}




\begin{tabular}{|c|c|}
\hline Parameters & Value/Size \\
\hline Data Rate & $11 \mathrm{Mbps}$ \\
\hline Radio Propagation & Direct Sequence \\
\hline Transport Protocol & TCP \\
\hline MAC Layer Protocol & MAC/IEEE 802.11 \\
\hline Transmission Power & $0.005 \mathrm{~W}$ \\
\hline Antenna Type & Omni Directional \\
\hline
\end{tabular}

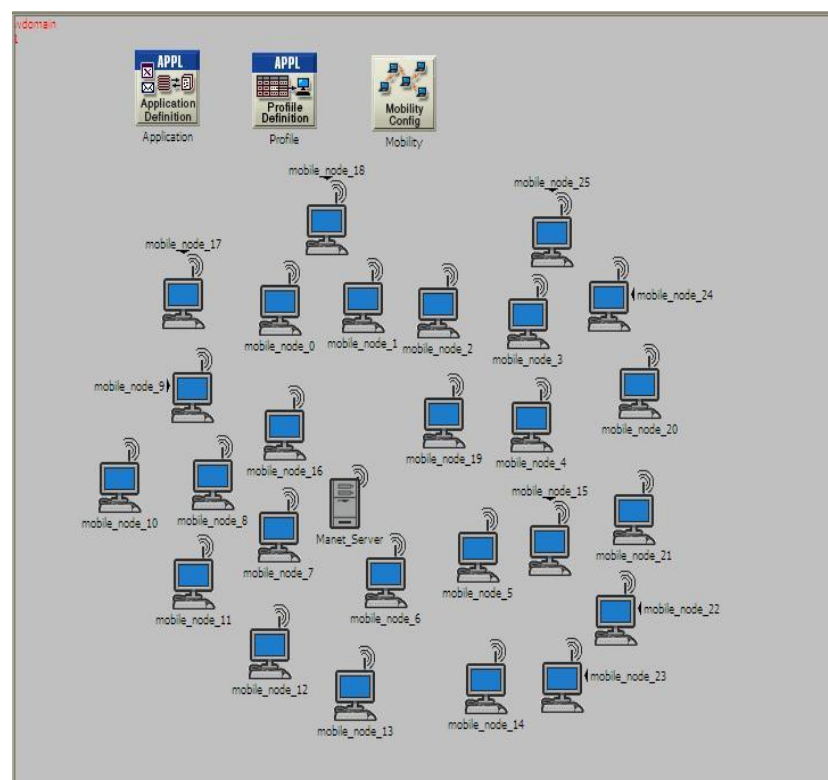

Fig 2: Simulation Scenario 1: Nodes Density 25 Nodes

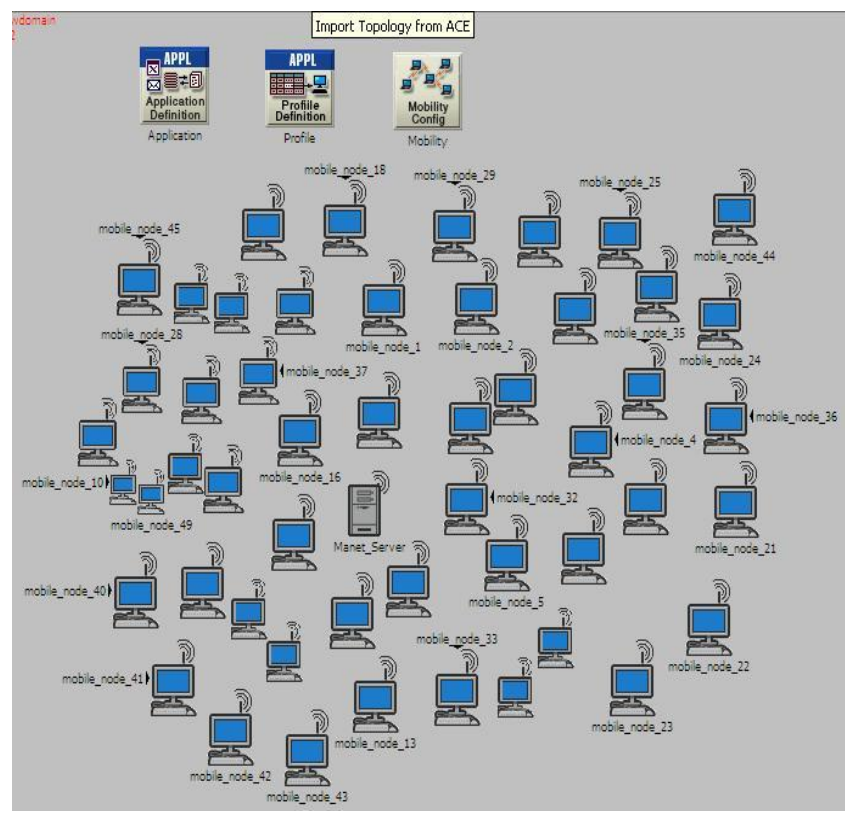

Fig 3: Simulation Scenario 2: Nodes Density 50 Nodes

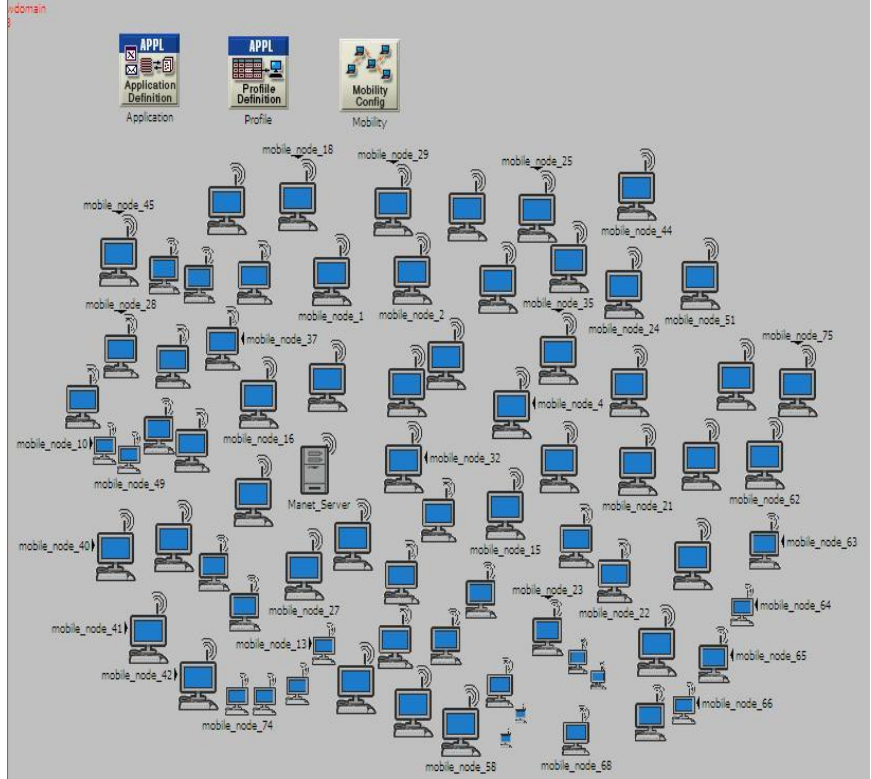

Fig 4: Simulation Scenario 3: Nodes Density 75 Nodes

\subsection{Performance Matrices}

\subsubsection{Wireless LAN (WLAN) Delay}

The average interval of time $b / w$ the generation of the data packets and the successful delivery of the data packets to all nodes in the wireless network is known as WLAN End to End delay. To calculate End to End Delay, discarded data packets or lost data packets are not considered [25].

\subsubsection{Wireless LAN (WLAN) Throughput}

The average rate for the successful delivery of data packets between nodes is known as wireless LAN throughput measured in bits/sec. the demand of every network is to have a higher value of throughput [26].

\subsubsection{Wireless LAN (WLAN) Network Load}

The total amount of load submitted by all higher-level network layers to all nodes in the network. WLAN network load is denoted in bits/sec [27]. The higher amount of the network load is due to the higher amount of traffic coming in the network; hence the network becomes congested and it's difficult to successfully handle all of this traffic in the network. Many approaches are introduced so that the network can manage a higher amount of traffic that may cause to degrades the performance of the network [28].

\subsubsection{Routing Traffic Sent}

The amount of routing control information in bits/sec that is compulsory to be sent by the routing protocols to all the nodes so that all the nodes in a network must have knowledge about all the available paths in order to send/receive data packets to/from the nodes.

\subsubsection{Routing Traffic Received}

The amount of routing control information in bits/sec that a node receives from the initiating source node or intermediate source nodes.

\section{RESULTS AND DISCUSSION 4.1 Time-Average WLAN Delay}

Based on the simulation results of time-average WLAN delay, as the number of nodes increases the WLAN delay of OLSR remains lesser and uniform as compared to DSR and TORA. TORA having a higher value of WLAN delay in comparison 
to DSR reactive routing protocol and OLSR proactive routing protocol. DSR shows medium WLAN delay as compared to TORA and OLSR. The maximum values of WLAN delay are highlighted in Table 2.

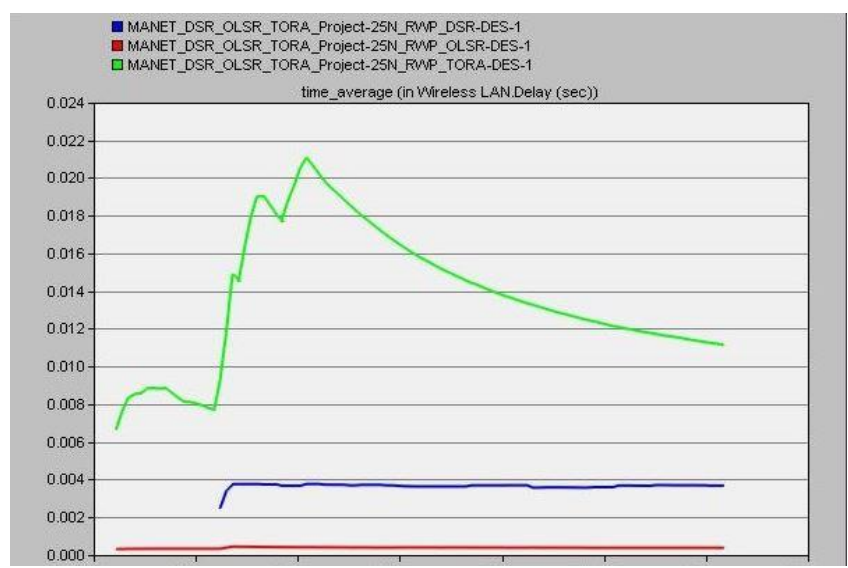

Fig 5: WLAN Delay: Nodes Density 25 Nodes

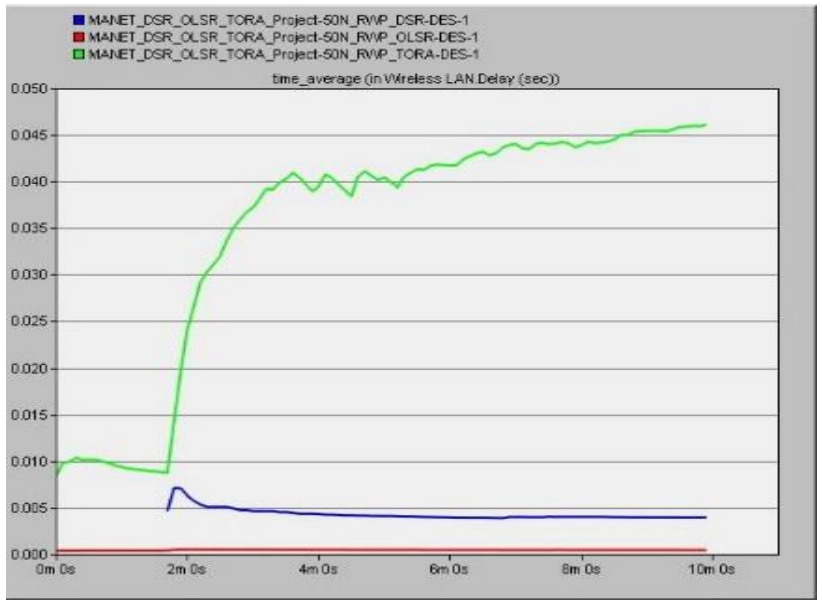

Fig 6: WLAN Delay: Nodes Density 50 Nodes

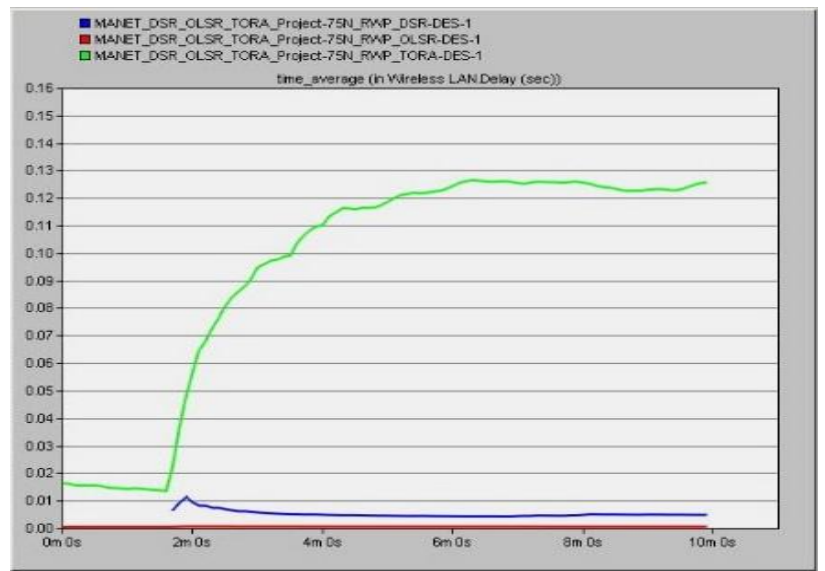

Fig 7: WLAN Delay: Nodes Density 75 Nodes

Table 2. Time Average WLAN Delay

\begin{tabular}{|c|c|c|c|}
\hline $\begin{array}{c}\text { Nodes } \\
\text { Density }\end{array}$ & DSR & TORA & OLSR \\
\hline 25 Nodes & $3.8 \mathrm{~ms}$ & $21 \mathrm{~ms}$ & $0.5 \mathrm{~ms}$ \\
\hline 50 Nodes & $7.5 \mathrm{~ms}$ & $46.5 \mathrm{~ms}$ & $0.625 \mathrm{~ms}$ \\
\hline 75 Nodes & $12 \mathrm{~ms}$ & $127 \mathrm{~ms}$ & $1 \mathrm{~ms}$ \\
\hline
\end{tabular}

\subsection{Time-Average WLAN Throughput}

Based on the simulation results of WLAN throughput as th number of nodes increases OLSR shows higher throughput as compared to DSR and TORA. Whereas DSR and TORA show approximately similar WLAN throughput is reduced quantity. The maximum values of WLAN throughput are highlighted in Table 3.

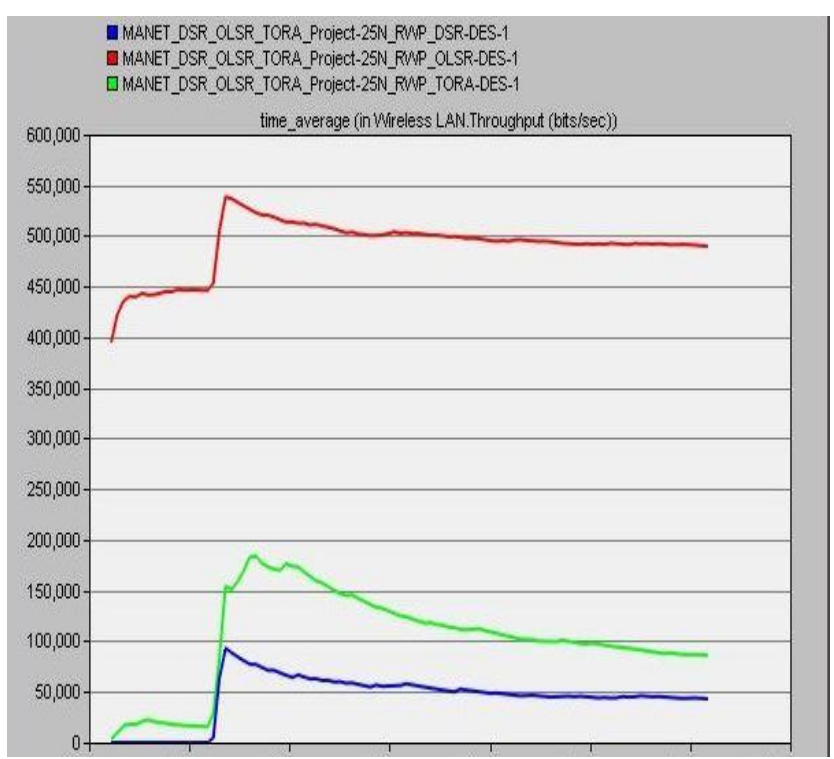

Fig 8: WLAN Throughput: Nodes Density 25 Nodes

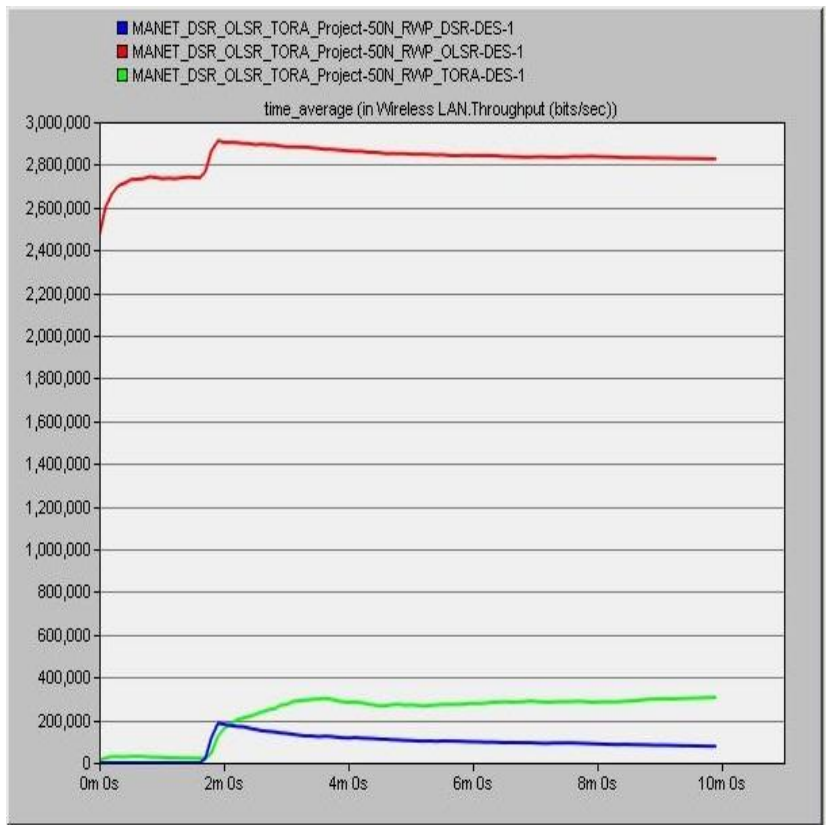

Fig 9: WLAN Throughput: Nodes Density 50 Nodes 


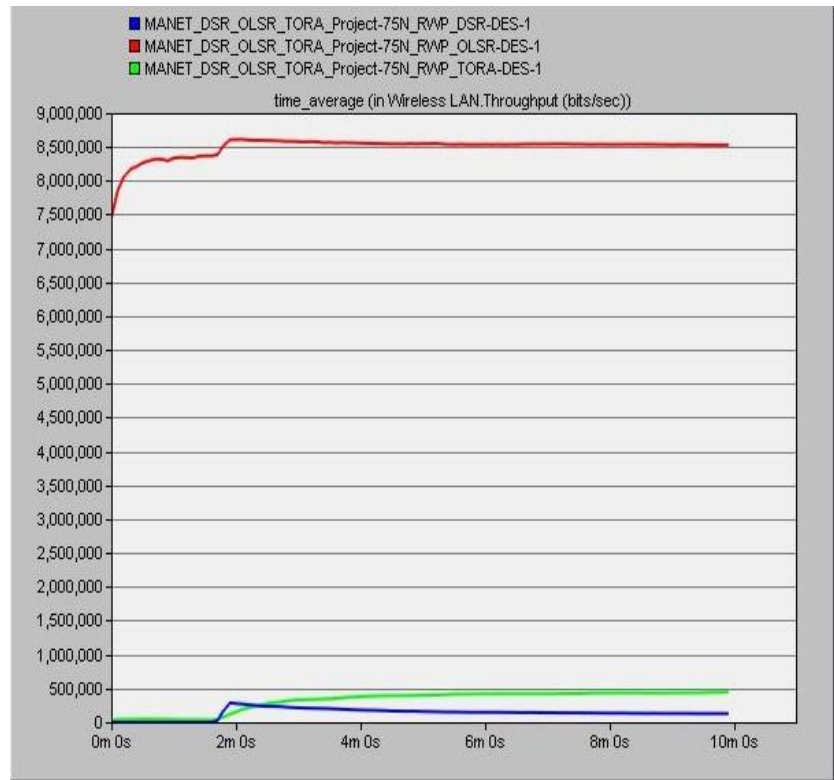

Fig 10: WLAN Throughput: Nodes Density 75 Nodes

Table 3. Time Average WLAN Throughput

\begin{tabular}{|c|c|c|c|}
\hline $\begin{array}{c}\text { Nodes } \\
\text { Density }\end{array}$ & DSR & TORA & OLSR \\
\hline 25 Nodes & $92 \mathrm{Kbps}$ & $183 \mathrm{Kbps}$ & $540 \mathrm{Kbps}$ \\
\hline 50 Nodes & $183 \mathrm{Kbps}$ & $305 \mathrm{Kbps}$ & $2920 \mathrm{Kbps}$ \\
\hline 75 Nodes & $284 \mathrm{Kbps}$ & $448 \mathrm{Kbps}$ & $8650 \mathrm{Kbps}$ \\
\hline
\end{tabular}

\subsection{Time-Average WLAN Network Load}

Based on the simulation results of the WLAN network load as the number of nodes increases w.r.t time, OLSR and TORA offer the higher value of WLAN network load to the MANET server means these protocols making MANET server overburdened. Whereas DSR offers a lower value of WLAN network load to the MANET server. The maximum values of the WLAN network load are highlighted in Table 4.

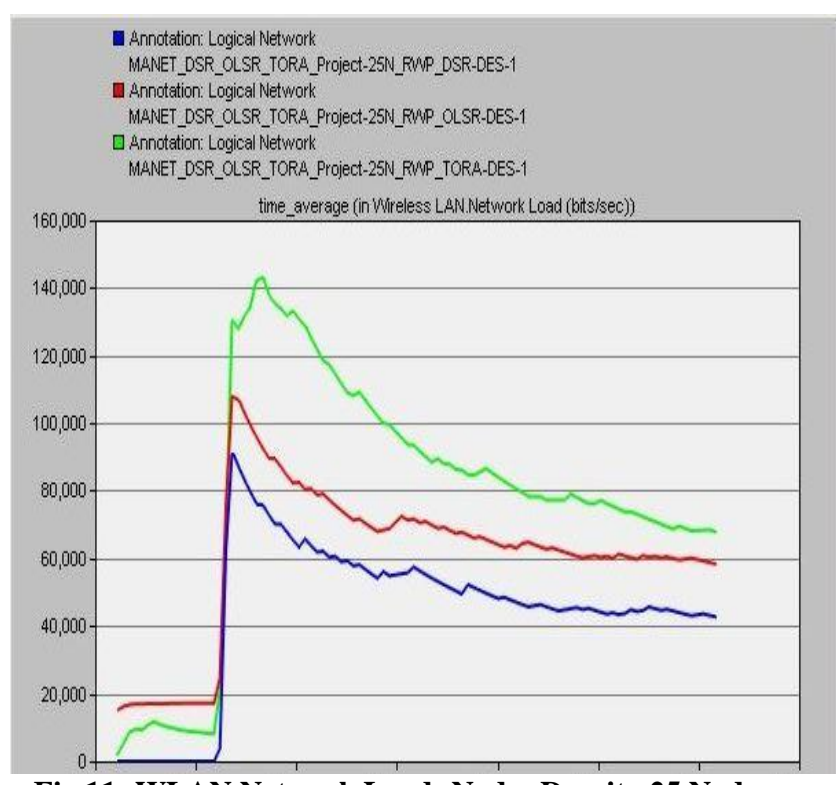

Fig 11: WLAN Network Load: Nodes Density 25 Nodes

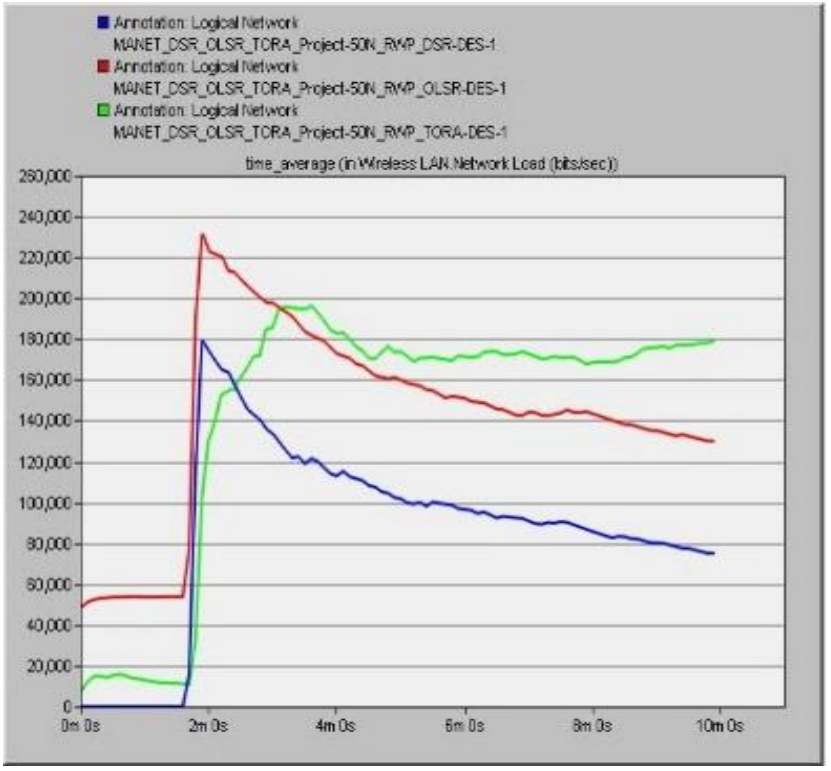

Fig 12: WLAN Network Load: Nodes Density 50 Nodes

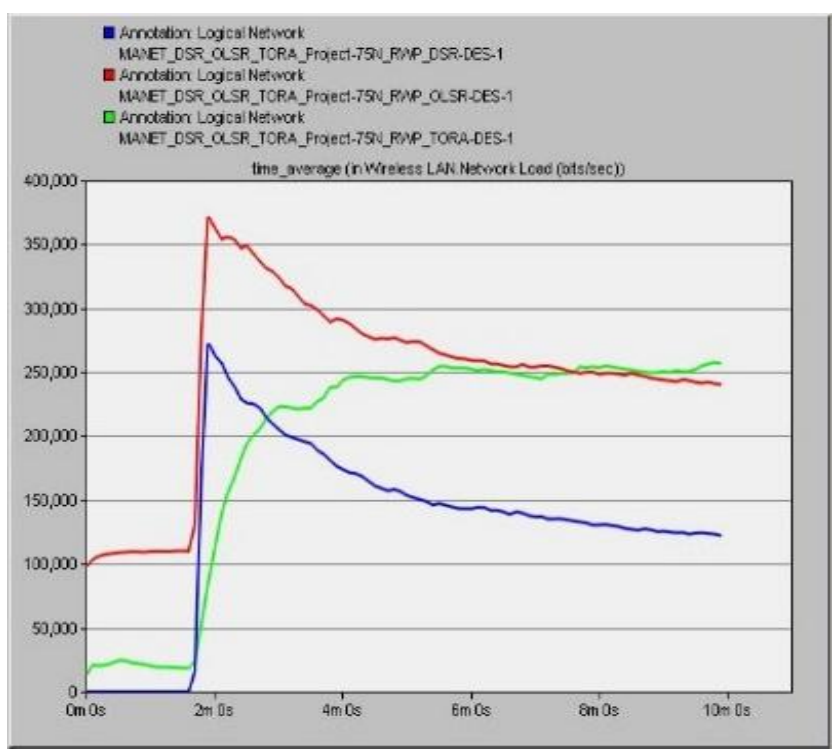

Fig 13: WLAN Network Load: Nodes Density 75 Nodes

Table 4. Time Average WLAN Network Load

\begin{tabular}{|c|c|c|c|}
\hline $\begin{array}{c}\text { Nodes } \\
\text { Density }\end{array}$ & DSR & TORA & OLSR \\
\hline 25 Nodes & $91 \mathrm{Kbps}$ & $143 \mathrm{Kbps}$ & $108 \mathrm{Kbps}$ \\
\hline 50 Nodes & $180 \mathrm{Kbps}$ & $198 \mathrm{Kbps}$ & $230 \mathrm{Kbps}$ \\
\hline 75 Nodes & $273 \mathrm{Kbps}$ & $259 \mathrm{Kbps}$ & $370 \mathrm{Kbps}$ \\
\hline
\end{tabular}

\subsection{Time-Average Routing Traffic Sent}

Based on simulation results of routing traffic sent at nodes the density of 25 nodes, routing traffic sent by the DSR is very less as compared to TORA and OLSR, moderate by the OLSR and high by the TORA. As the Nodes Density increase, routing traffic sent by the DSR again remains less as compared to TORA and OLSR whereas moderate again by the OLSR and high by the TORA. It means that DSR required less routing information for data packets forwarding, OLSR required the moderate value of routing information butTORA required a very high amount of routing information 
for data packets forwarding as nodes density increases. The maximum values of the routing traffic sent are highlighted in Table 5.

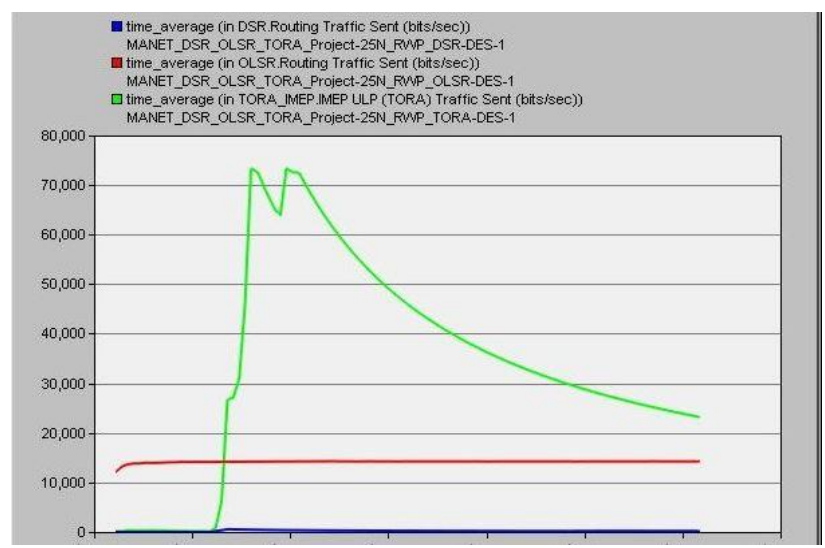

Fig 14: Routing Traffic Sent: Nodes Density 25 Nodes

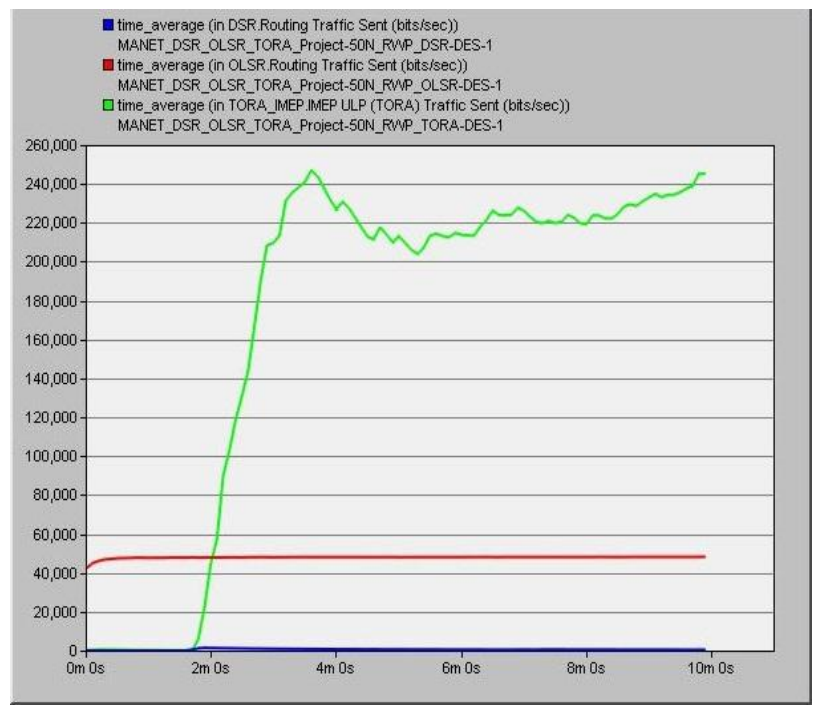

Fig 15: Routing Traffic Sent: Nodes Density 50 Nodes

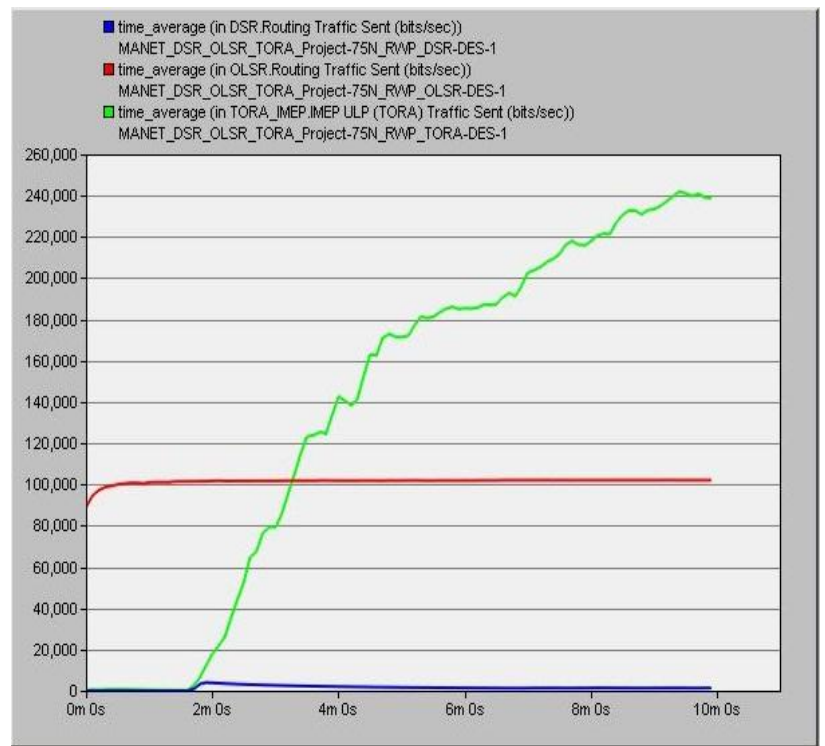

Fig 16: Routing Traffic Sent: Nodes Density 75 Nodes
Table 5. Time Average Routing Traffic Sent

\begin{tabular}{|c|c|c|c|}
\hline $\begin{array}{c}\text { Nodes } \\
\text { Density }\end{array}$ & DSR & TORA & OLSR \\
\hline 25 Nodes & $91 \mathrm{Kbps}$ & $143 \mathrm{Kbps}$ & $108 \mathrm{Kbps}$ \\
\hline 50 Nodes & $180 \mathrm{Kbps}$ & $198 \mathrm{Kbps}$ & $230 \mathrm{Kbps}$ \\
\hline 75 Nodes & $273 \mathrm{Kbps}$ & $259 \mathrm{Kbps}$ & $370 \mathrm{Kbps}$ \\
\hline
\end{tabular}

\subsection{Time-Average Routing Traffic Received}

Based on the simulation results of routing traffic sent, at low nodes density, routing traffic received by the DSR is very less as compared to TORA and OLSR, moderate by the OLSR and high by the TORA. As the Nodes Density increase, routing traffic received by the DSR again remains less as compared to TORA and OLSR whereas moderate by the TORA and high by the OLSR. Routing traffic received is always greeter than routing traffic sent because intermediate nodes add more routing information with the data packets. The maximum values of the routing traffic received are highlighted in Table 6.

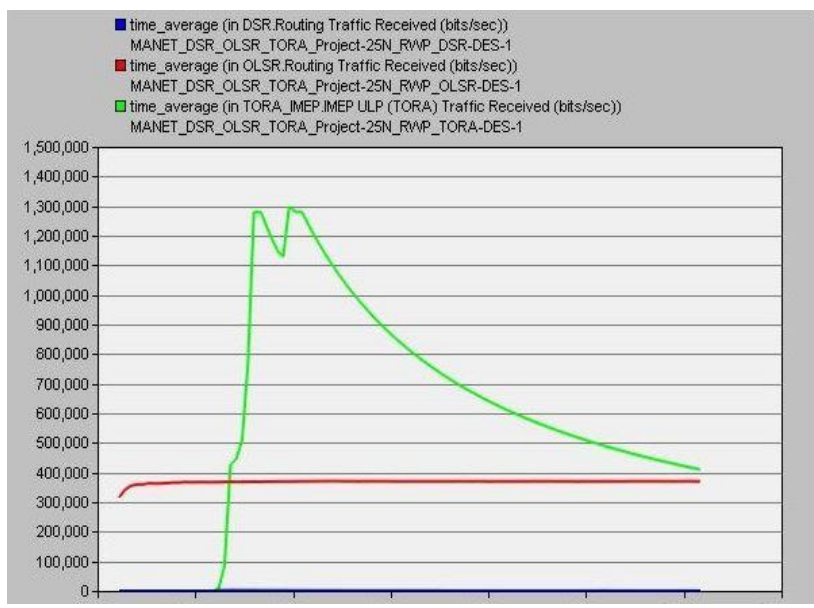

Fig 17: Routing Traffic Received: Nodes Density 25 Nodes

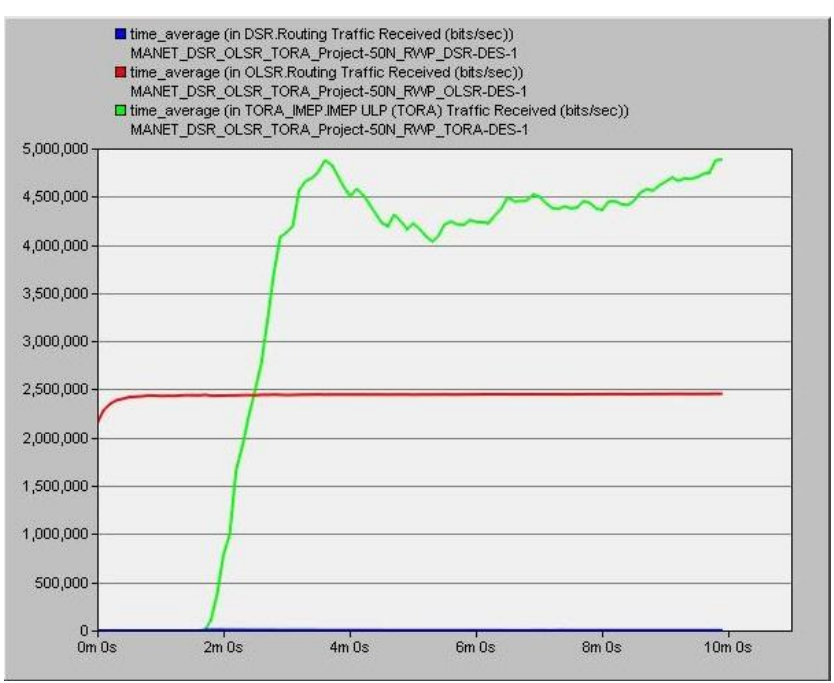

Fig 18: Routing Traffic Received: Nodes Density 50 Nodes 


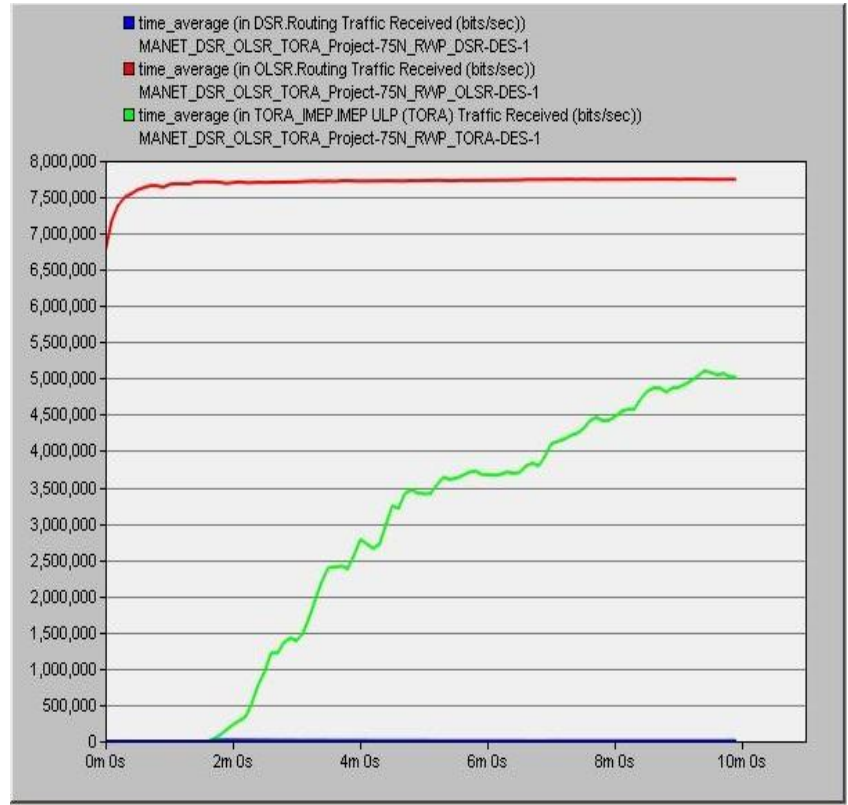

Fig 19: Routing Traffic Received: Nodes Density 75 Nodes

Table 6. Time Average Routing Traffic Received

\begin{tabular}{|c|c|c|c|}
\hline $\begin{array}{c}\text { Nodes } \\
\text { Density }\end{array}$ & DSR & TORA & OLSR \\
\hline 25 Nodes & $2.05 \mathrm{Kbps}$ & $1300 \mathrm{Kbps}$ & $370 \mathrm{Kbps}$ \\
\hline 50 Nodes & $7.05 \mathrm{Kbps}$ & $4850 \mathrm{Kbps}$ & $2460 \mathrm{Kbps}$ \\
\hline 75 Nodes & $16.3 \mathrm{Kbps}$ & $5100 \mathrm{Kbps}$ & $7780 \mathrm{Kbps}$ \\
\hline
\end{tabular}

\section{CONCLUSION}

With respect to time average results of WLAN delay, by increasing the density of the nodes, OLSR has a very small delay as compared to DSR and TORA, whereas DSR has a moderate delay as compared to OLSR and TORA. TORA has a very high delay as compared to OLSR and DSR. DSR also belongs to the category of reactive protocols but it has a short delay as compared to TORA. With respect to time average results of WLAN throughput, by increasing the density of the nodes, OLSR shows very high throughput as compared to DSR and TORA. TORA has moderate WLAN throughput and DSR has very little throughput. It was oticed earlier that OLSR has a very small WLAN delay hat is the reason it shows the highest throughput as compared to TORA and DSR. TORA has a very high delay but its throughput is better than DSR. DSR offers less throughput as compared to TORA and OLSR. With respect to time average results of WLAN network load, by increasing the density of the nodes, OLSR provides a maximum load to all WLAN layers of MANET whereas TORA and DSR provide a moderate WLAN network load. Higher WLAN network load to all WLAN layers of protocol stack makes challenges for the network to effectively handle this high value of network load because the network becomes overburdened. So DSR is more effective with respect to the WLAN network load. With respect to time average results of routing overhead or routing traffic sent and received, TORA has very high routing traffic sent, moderate routing traffic was sent by OLSR and a very small amount of routing traffic sent by DSR. Whereas in the case of routing traffic received, OLSR has very high routing traffic received, TORA has a high amount of routing traffic received and DSR has very less routing traffic received. It means that DSR is best with respect to routing traffic sent and received or routing overhead as compared to both TORA and OLSR whereas OLSR the proactive protocol performs worse with respect to routing traffic sent and received or routing overhead. In short, OLSR has the best performance as compared to DSR and TORA in case of WLAN delay and throughput. Future work will be the enhancement of these routing protocols.

\section{REFERENCES}

[1] B. Ravi, K. K. Patil, U. K. K. Shenoy, and B. A. Holla, "A simulation study of the impact of low and high mobility on MANET routing protocols," IEEE International Conference on Energy, Communication, Data Analytics and Soft Computing (ICECDS), pp. 1423-1428, 2017.

[2] A. M. E. Ejmaa, S. Subramaniam, Z. A. Zukarnain, and Z. M. Hanapi, "Neighbor-based dynamic connectivity factor routing protocol for mobile ad hoc network," IEEE Access, vol. 4, pp. 8053-8064, 2016.

[3] Y. Fang, Y. Zhou, X. Jiang, and Y. Zhang, "Practical performance of MANETs under limited buffer and packet lifetime," IEEE Systems Journal, vol. 11, no. 2, pp. 995-1005, 2017.

[4] G. Singal et al., "Multi-constraints link stable multicast routing protocol in MANETs," Ad Hoc Networks, vol. 63, pp. 115-128, 2017.

[5] B. Yang, Y. Chen, Y. Cai, and X. Jiang, "Packet delivery ratio/cost in MANETs with erasure coding and packet replication," IEEE Transactions on Vehicular Technology, vol. 64, no. 5, pp. 2062-2070, 2015.

[6] W.-K. Kuo and S.-H. Chu, "Energy efficiency optimization for mobile ad hoc networks," IEEE Access, vol. 4, pp. 928-940, 2016.

[7] N. Raza, M. U. Aftab, M. Q. Akbar, O. Ashraf, and M. Irfan, "Mobile ad-hoc networks applications and its challenges," Communication and Networks, 2016.

[8] Raza, N., Jabbar, S., Han, J., \& Han, K. (2018, June). Social vehicle-to-everything (V2X) communication model for intelligent transportation systems based on 5G scenario. In Proceedings of the 2nd International Conference on Future Networks and Distributed Systems, pp. 1-8, 2018.

[9] Raza, N., Akbar, M. Q., Soofi, A. A., \& Akbar, S. (2019). Study of smart grid communication network architectures and technologies. Journal of Computer and Communications, vol. 7, no. 3, pp.19-29, 2019.

[10] Rehman, H. U., Asif, M., \& Ahmad, M. (2017, "Future applications and research challenges of iot". International Conference on Information and Communication Technologies, pp. 68-74), 2017.

[11] N. A. Mahiddin, N. I. Sarkar, and B. Cusack, "An Internet Access Solution: MANET Routing and a Gateway Selection Approach for Disaster Scenarios," The Review of Socionetwork Strategies, vol. 11, no. 1, pp. 47-64, 2017.

[12] M. Gowtham and K. Subramaniam, "Congestion control and packet recovery for cross layer approach in manet," Cluster Computing, pp. 1-8, 2018. 
[13] A. Taha, R. Alsaqour, M. Uddin, M. Abdelhaq, and T. Saba, "Energy Efficient multIpath routing protocol for Mobile ad-hoc Network using the Fitness Function," IEEE Access, vol. 5, pp. 10369-10381, 2017.

[14] P. T. Selvi and C. S. GhanaDhas, "A Novel Algorithm for Enhancement of Energy Efficient Zone Based Routing Protocol for MANET," Mobile Networks and Applications, pp. 1-11, 2018.

[15] A. Singh, G. Singh, and M. Singh, "Comparative Study of OLSR, DSDV, AODV, DSR and ZRP Routing Protocols Under Blackhole Attack in Mobile Ad Hoc Network," Intelligent Communication, Control and Devices: Springer, pp. 443-453, 2018.

[16] U. Draz, T. Ali, S. Yasin, and A. Shaf, "Evaluation based analysis of packet delivery ratio for AODV and DSR under UDP and TCP environment," IEEE International Conference on Computing, Mathematics and Engineering Technologies (iCoMET), pp. 1-7, 2018.

[17] M. Zhang, M. Yang, Q. Wu, R. Zheng, and J. Zhu, "Smart perception and autonomic optimization: A novel bio-inspired hybrid routing protocol for MANETs," Future Generation Computer Systems, vol. 81, pp. 505513, 2018.

[18] K. Adhvaryu and P. Kamboj, "Performance comparison between multicast routing protocols in MANET," 4th IEEE Uttar Pradesh Section International Conference on Electrical, Computer and Electronics (UPCON), pp. 1620, 2017.

[19] A. A. Al-khatib and R. Hassan, "Performance evaluation of AODV, DSDV, and DSR routing protocols in MANET using NS-2 simulator," Springer International Conference of Reliable Information and Communication Technology, pp. 276-284, 2017.

[20] K. C. Purohit, S. C. Dimri, and S. Jasola, "Performance evaluation of various MANET routing protocols for adaptability in VANET environment," International Journal of System Assurance Engineering and Management, vol. 8, no. 2, pp. 690-702, 2017.
[21] M. Kaur and M. Sharma, "Energy Efficient Routing Protocol for MANET," Springer Ambient Communications and Computer Systems, pp. 201-212, 2018.

[22] M. Gochar and R. Singh, "WCA based re-clustering approach in DSR and OLSR routing protocols in MANET," IEEE International Conference on Recent Innovations in Signal processing and Embedded Systems (RISE), pp. 485-493, 2017.

[23] Q. Razouqi, A. Boushehri, and M. Gaballah, "Performance analysis for diverse simulation scenarios for DSDV, DSR and AODV MANET routing protocols," IEEE 13th International Computer Engineering Conference (ICENCO), pp. 30-35, 2017.

[24] A. Roy and T. Deb, "Performance Comparison of Routing Protocols in Mobile Ad Hoc Networks," Springer Proceedings of the International Conference on Computing and Communication Systems, pp. 33-48, 2018.

[25] A. Radwan, T. M. Mahmoud, and E. H. Houssein, "Performance measurement of some mobile ad hoc network routing protocols," International Journal of Computer Science and Informatics, vol. 8, no. 1, pp. 107112, 2011.

[26] P. Singh, E. Barkhodia, and G. K. Walia, "Evaluation of various Traffic loads in MANET with DSR routing protocol through use of OPNET Simulator," International Journal of Distributed and Parallel Systems, vol. 3, pp. 75-83, 2012.

[27] G. S. Aujla and S. S. Kang, "Comparative Analysis of AODV, DSR, GRP, OLSR and TORA by varying Number of Nodes with FTP and HTTP Applications over MANETs," International Journal of Computer Applications, vol. 65, no. 2, pp. 18-26, 2013

[28] R. Al-Ani, "Simulation and performance analysis evaluation for variant MANET routing protocols," International Journal of Advancements in Computing Technology, vol. 3, no. 1, pp. 1-12, 2011 